\title{
Prevalence and Distribution of Dental Anomalies among Orthodontic Patients of Kathmandu, Nepal
}

\author{
Dr Sanjay Prasad Gupta,' Dr Shristi Rauniyar2 \\ Orthodontics and Dentofacial Orthopedics Unit, Department of Dentistry, Tribhuvan University Teaching Hospital, \\ Institute of Medicine, Tribhuvan University, Nepal \\ 2Dental Villa, Orthodontic Center \& Speciality Dental Clinic, Kathmandu
}

Correspondence: Dr. Sanjay Prasad Gupta; Email: sanjayaguptazooo@gmail.com

\section{ABSTRACT}

Introduction: Dental anomalies are commonly seen during regular dental check-up. It occurs due to abnormal morphodifferentiation of teeth during different stages of tooth development. The purpose of this study was to find out the of dental anomalies among orthodontic patients of Kathmandu, Nepal.

Materials \& Method: A total of 601 patients (242 males and 359 females) of aged 10 to 35 years (mean age= $16.42 \pm 3.42$ years) who require orthodontic treatment were selected. The patients were assessed clinically and dental panoramic radiographs were evaluated for disturbance in number and other anomalies. A chi-square test was used to determine the difference in the prevalence of dental anomalies between genders and among different classes of malocclusion.

Result: The prevalence of dental anomalies was $15.3 \%$ that is 92 participants were exhibited at least one dental anomaly among 601 orthodontic patients. Among dental anomalies, hypodontia was the most prevalent (7.48\%) followed by hyperdontia (2.99\%), microdontia $(2.16 \%)$, macrodontia $(0.66 \%)$, transposition $(0.66 \%)$, taurodontism $(0.49 \%)$, double teeth $(0.33 \%)$, amelogenesis imperfecta $(0.33 \%)$ and dentinogenesis imperfecta $(0.16 \%)$. The prevalence of oligodontia was $0.33 \%$. There were no statistically significant difference in prevalence of anomalies in between gender and among different classes of malocclusion.

Conclusion: Prevalence and distribution of some dental anomalies in orthodontic patients of Kathmandu differed from other studies. Maxillary lateral incisor was the most commonly missing and microdontic tooth. Orthodontists have the responsibility to observe each patient carefully for dental anomalies to correct or improvise this condition without any complications.

Keywords: Association, Dental anomalies, Orthodontic patients, Prevalence.

\section{INTRODUCTION}

Dental anomalies are frequently seen during dental consultation. Dental anomalies are abnormal morphodifferentiation of teeth during different stages of tooth development. These anomalies may be acquired or occur due to genetic predispositions which seems to play more important role.' Genetic disorders cause many abnormalities before and after birth including anomalies in the number, size, morphology, position and structure. ${ }^{2}$ These anomalies can create disturbances in maxillary and mandibular dental arch lengths and occlusions; these problems might complicate orthodontic treatment planning. ${ }^{3}$

The prevalence of dental anomalies range between $12 \%-45 \%$ among different populations..$^{2,4-11}$

Tooth anomalies were more frequent in orthodontic patients than the general population, and were usually associated with certain malocclusions. ${ }^{12,13}$ If not detected, they can complicate dental and orthodontic treatment. Therefore, orthodontists and general dental professional should carefully investigate. The possible cause of the variance in these reports might be due to race, different ethinicity, sample selection and size, type of dental anomalies and malocclusion.

Study representing the dental anomalies in orthodontic patients in Nepal has not been done so far. Therefore this study was conducted to determine the prevalence of dental anomalies in orthodontic patients of Kathmandu, Nepal.

\section{MATERIALS AND METHOD}

Six hundred one participants were selected among the orthodontic patients who came for orthodontic treatment in orthodontic unit, Tribhuvan university teaching hospital \& Dental villa-Orthodontic center \& speciality dental clinic, Kathmandu, Nepal. Sample size for this study was determined by using $n=Z^{2} p q / d^{2}$, 
where $Z=1.96$, value of $p$ is taken as $0.5, q=1-p=0.5$, allowable error $(d)=0.04(96 \%)$ and $n$ is required sample size. Based on these parameters, the required sample size was 600.25. Hence, total 601 patients were selected.

Inclusion criteria of this study were patients between 1035 years of age who came for orthodontic treatment and gave consent to this study and presence of good quality panoramic radiograph and from a single source.

Patients were excluded who had extraction or previous orthodontic treatment, systemic disease or craniofacial anomalies/congenital syndrome.

Ethical approval was obtained from institutional review committee of Institute of Medicine before conducting this study.

After obtaining the informed consent from the patients or their parents, demographic details along with detailed medical, dental and family histories were obtained.

All individuals were evaluated by a single operator (author), and occlusal relationships were evaluated at centric occlusion, which was achieved by asking the subject to swallow and then to bite on his/her teeth together. It was categorized according to Angle's classification of malocclusion, i.e. Class I, Class II and Class III malocclusions. ${ }^{14}$

The criteria presented by Soames JV et $\mathrm{al}^{15}$ were used for the descriptions of anomalies. Following dental anomalies were assessed:

1. Disturbance in number of teeth (Hypodontia \& hyperdontia).

2. Disturbance in size of teeth (Macrodontia \& microdontia).

3. Disturbance in location of teeth (Transposition).

4. Disturbance in form of teeth (Taurodontism \& double tooth).

5. Disturbance in structure of teeth (Amelogenesis imperfecta, dentinogenesis imperfecta, dentine displasia)

In addition to the intraoral examination, dental panoramic radiograph was also evaluated for any dental anomalies. The panoramic radiographs were analyzed by trained observer (author) who followed a pre-established protocol: general observation of the teeth including third molar, followed by a systematic analysis of the erupted and unerupted teeth in each quadrant. A tooth was diagnosed as congenitally missing if the mineralization of its crown could not be identified on orthopantomogram. The evaluation of digital orthopantamogram was carried out on a computer screen with a resolution of $1,280 \times 800$ pixels.

\section{Statistical Analysis}

Data obtained were transferred to MS-excel sheet. The data were verified and analysed statistically using SPSS Statistics Version 21.0 (Armonk, NY: IBM Corp.) with confidence level set at $95 \%(P<0.05)$ to test for significance. The prevalence of dental agenesis among orthodontic patients were descriptively analysed. Pearson's Chi-square test was used at 5\% significance level to investigate the significance of differences of dental anomalies between gender and among different classes of malocclusion.

\section{RESULT}

This study found that among the total of 601 participants, 242 (40.27\%) were male while 359 (59.73\%) were female (Fig. 1) and the mean age was $16.42 \pm 3.42$ years.

Out of 601 patients, 92 (15.30\%) exhibited at least one dental anomaly, while 509 patients (84.69\%) showed no dental anomalies in orthodontic patients.

The frequencies of selected anomalies, sex distribution and statistical differences between sexes are shown in Table 1. Differences in prevalence rates of each dental anomaly by sex were analyzed by using chi-square test and the related $P$ values were calculated for each anomaly. No statistically significant correlation were found between dental anomalies and patient's gender.

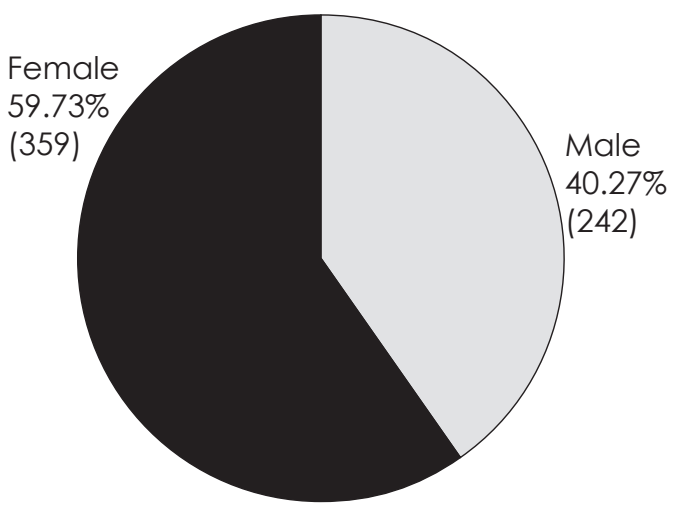

Fig. 1 Frequency of gender distribution 
Table 1: Prevalence and distribution of dental anomalies among males and females in orthodontic patients

\begin{tabular}{|l|c|c|c|c|}
\hline \multicolumn{1}{|c|}{ Anomalies } & Males & Females & Total (n=601) & p-value (chi-square) \\
\hline Hypodontia & $14(2.32 \%)$ & $31(5.15 \%)$ & $45(7.48 \%)$ & 0.193 \\
\hline Hyperdontia & $10(1.66 \%)$ & $8(1.33 \%)$ & $18(2.99 \%)$ & 0.179 \\
\hline Microdontia & $4(0.66 \%)$ & $9(1.49 \%)$ & $13(2.16 \%)$ & 0.480 \\
\hline Macrodontia & $1(0.16 \%)$ & $3(0.49 \%)$ & $4(0.66 \%)$ & 0.532 \\
\hline Transposition & $1(0.16 \%)$ & $3(0.49 \%)$ & $4(0.66 \%)$ & 0.532 \\
\hline Double teeth & $1(0.16 \%)$ & $1(0.16 \%)$ & $2(0.33 \%)$ & 0.779 \\
\hline Taurodontism & $1(0.16 \%)$ & $2(0.33 \%)$ & $3(0.49 \%)$ & 0.8063 \\
\hline Amelogenesis Imperfecta & $1(0.16 \%)$ & $1(0.16 \%)$ & $2(0.33 \%)$ & 0.779 \\
\hline Dentinogenesis Imperfecta & $0(0 \%)$ & $1(0.16 \%)$ & $1(0.16 \%)$ & 0.411 \\
\hline Dentin Displasia & $0(0 \%)$ & $0(0 \%)$ & $0(0 \%)$ & - \\
\hline Total & $33(5.49 \%)$ & $59(9.81 \%)$ & $92(15.30 \%)$ & \\
\hline
\end{tabular}

$\mathrm{p}>0.05=$ Statistically non significant

Table 2: Prevalence and distribution of dental anomalies among different malocclusions in orthodontic patients

\begin{tabular}{|l|c|c|c|c|c|}
\hline \multicolumn{1}{|c|}{ Anomalies } & $\begin{array}{c}\text { Class I } \\
\mathbf{3 9 4}(\mathbf{6 5 . 5 5 \% )}\end{array}$ & $\begin{array}{c}\text { Class II } \\
\mathbf{1 8 6 ( 3 0 . 9 4 \% )}\end{array}$ & $\begin{array}{c}\text { Class III } \\
\mathbf{2 1}(\mathbf{3 . 4 9 \% )}\end{array}$ & Total (n=601) & $\begin{array}{c}\text { p-value } \\
\text { (chi-square) }\end{array}$ \\
\hline Hypodontia & $31(7.86 \%)$ & $13(6.98 \%)$ & $1(4.76 \%)$ & $45(7.48 \%)$ & 0.829 \\
\hline Hyperdontia & $12(3.04 \%)$ & $5(2.68 \%)$ & $1(4.76 \%)$ & $18(2.99 \%)$ & 0.865 \\
\hline Microdontia & $8(2.03 \%)$ & $4(2.15 \%)$ & $1(4.76 \%)$ & $13(2.16 \%)$ & 0.704 \\
\hline Macrodontia & $2(0.50 \%)$ & $2(1.07 \%)$ & $0(0 \%)$ & $4(0.66 \%)$ & 0.683 \\
\hline Transposition & $2(0.50 \%)$ & $1(0.53 \%)$ & $1(4.76 \%)$ & $4(0.66 \%)$ & 0.063 \\
\hline Double teeth & $1(0.25 \%)$ & $1(0.53 \%)$ & $0(0 \%)$ & $2(0.33 \%)$ & 0.827 \\
\hline Taurodontism & $1(0.25 \%)$ & $2(1.07 \%)$ & $0(0 \%)$ & $3(0.49 \%)$ & 0.401 \\
\hline Amelogenesis Imperfecta & $1(0.25 \%)$ & $1(0.53 \%)$ & $0(0 \%)$ & $2(0.33 \%)$ & 0.827 \\
\hline Dentinogenesis Imperfecta & $1(0.25 \%)$ & $0(0 \%)$ & $0(0 \%)$ & $1(0.16 \%)$ & 0.769 \\
\hline Dentin Displasia & $0(0 \%)$ & $0(0 \%)$ & $0(0 \%)$ & $0(0 \%)$ & - \\
\hline Total & $59(14.97 \%)$ & $29(15.59 \%)$ & $4(19.04 \%)$ & $92(15.30 \%)$ & \\
\hline
\end{tabular}

$p>0.05=$ Statistically non significant

Table 2 and Figure 2 depict the frequencies of selected anomalies, distribution of types of malocclusion and statistical difference between different types of malocclusion. Differences in prevalence rates of each dental anomaly by types of malocclusion were analyzed by using chi-square test and the related $P$ values were calculated for each anomaly. No statistically significant correlation were found between dental anomalies and malocclusion.

Hypodontia was the most common dental anomaly in the present study followed in descending order by hyperdontia (7.48\%), microdontia (2.16\%), macrodontia $(0.66 \%)$, transposition $(0.66 \%)$, taurodontism $(0.49 \%)$, double teeth $(0.33 \%)$, amelogenesis imperfecta $(0.33 \%)$, dentinogenesis imperfecta $(0.16 \%)$. The distribution of various anomalies is outlined.

The prevalence of dental agenesis (hypodontia) was $7.48 \%$ (45) excluding third molar. The prevalence of oligodontia was $0.33 \%$ (2). The total number of missing teeth were $72(0.42 \%)$ while excluding third molar (Table 3 \& Table 4).

This study showed that among missing teeth except third molars, the maxillary lateral incisor was the most lost by $48.61 \%$ followed by mandibular lateral incisor (19.44\%), mandibular central incisor (8.33\%), mandibular second premolar (6.94\%) and maxillary second premolar (5.55\%). The canine, first premolar, maxillary central incisor, second molar were rarely absent. There was no observation about the absence of the maxillary and mandibular first molars.

Hyperdontia were seen in 18 (2.99\%) patients. Microdontia was observed in $13(2.16 \%)$ of patients. Microdontia is very common in maxilla compared to mandible. The occurrence of macrodontia $(0.66 \%)$ was less common than microdontia. 


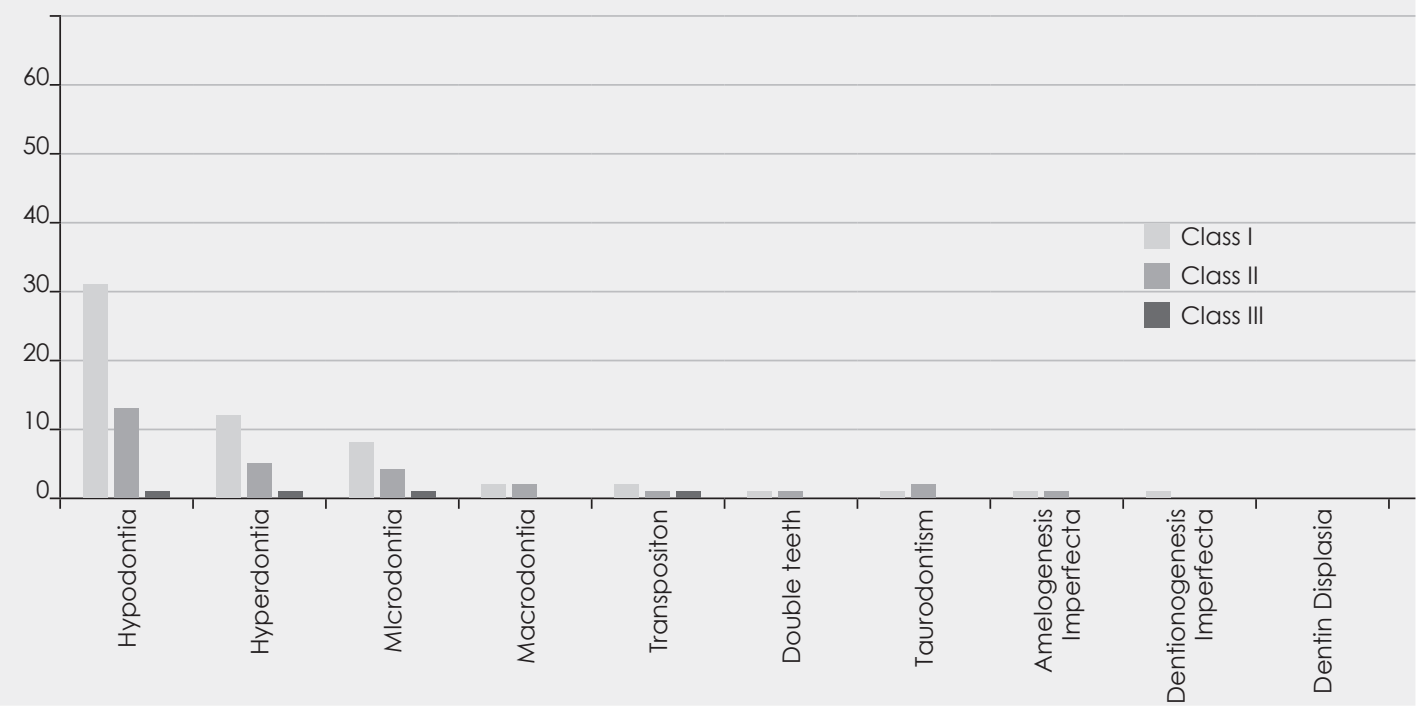

Fig. 2 Distribution of dental anomalies among different malocclusions in orthodontic patients

Table 3: Distribution of patients according to the number of missing teeth excluding third molar among all samples

\begin{tabular}{|c|c|c|c|c|c|c|c|}
\hline No. of missing teeth & $\begin{array}{l}\text { Missing of } 1 \\
\text { tooth }\end{array}$ & $\begin{array}{c}\text { Missing of } 2 \\
\text { teeth }\end{array}$ & $\begin{array}{l}\text { Missing of } 3 \\
\text { teeth }\end{array}$ & $\begin{array}{c}\text { Missing of } 4 \\
\text { teeth }\end{array}$ & $\begin{array}{c}\text { Missing of } 5 \\
\text { teeth }\end{array}$ & $\begin{array}{l}\text { Missing of } 6 \text { or } \\
\text { more teeth }\end{array}$ & Total \\
\hline No. of Patients & $25(4.15 \%)$ & $14(2.32 \%)$ & $2(0.33 \%)$ & $2(0.33 \%)$ & $0(0 \%)$ & $2(0.33 \%)$ & 45 (7.48\%) \\
\hline
\end{tabular}

Table 4: Number of missing teeth of the study sample according to the type of tooth and its location with percentage among missing teeth excluding the third molar

\begin{tabular}{|l|c|c|c|c|c|c|c|c|}
\hline $\begin{array}{c}\text { Type of } \\
\text { tooth }\end{array}$ & $\begin{array}{c}\text { Second } \\
\text { molar }\end{array}$ & First molar & $\begin{array}{c}\text { Second } \\
\text { premolar }\end{array}$ & $\begin{array}{c}\text { First premo- } \\
\text { lar }\end{array}$ & Canine & $\begin{array}{c}\text { Lateral inci- } \\
\text { sor }\end{array}$ & $\begin{array}{c}\text { Central } \\
\text { incisor }\end{array}$ & Sum \\
\hline Upper teeth & $0(0 \%)$ & $0(0 \%)$ & $4(5.55 \%)$ & $1(1.38 \%)$ & $3(4.16 \%)$ & $35(48.61 \%)$ & $0(0 \%)$ & $43(59.72 \%)$ \\
\hline Lower teeth & $2(2.77 \%)$ & $0(0 \%)$ & $5(6.94 \%)$ & $0(0 \%)$ & $2(2.77 \%)$ & $14(19.44 \%)$ & $6(8.33 \%)$ & $29(40.28 \%)$ \\
\hline Sum & $2(2.77 \%)$ & $0(0 \%)$ & $9(12.5 \%)$ & $1(1.38 \%)$ & $5(6.94 \%)$ & $49(68.05 \%)$ & $6(8.33 \%)$ & $72(100 \%)$ \\
\hline
\end{tabular}

Prevalence rate of transposition of teeth seen in this study is $0.66 \%$. Most common transposition is between maxillary lateral incisor and canine. There were $3(0.49 \%)$ cases of taurodontism. There were $2(0.33 \%)$ cases of double tooth, 2 cases of amelogenesis imperfecta and one case of dentinogenesis imperfecta seen in this study. None of any patient had dentine displasia in this study.

\section{DISCUSSION}

Although several studies assessed the prevalence of dental anomalies but only few studies conducted on orthodontic patients $2,8,16-20$ the reported results have been different in various racial and ethnic groups. Such type of studies were not conducted before, hence this study aimed to find out the prevalence of dental anomalies in orthodontic patients of Kathmandu, Nepal.

This study showed, the prevalence of dental anomalies was $15.30 \%$ that is 92 patients have at least one dental anomalies among 601 orthodontic patients of Kathmandu, Nepal. Among other anomalies, hypodontia was the most prevalent (7.48\%) followed by hyperdontia (2.99\%), microdontia (2.16\%), macrodontia (0.66\%), transposition(0.66\%), taurodontism (0.49\%), double teeth $(0.33 \%)$, amelogenesis imperfecta $(0.33 \%)$ and dentinogenesis imperfecta $(0.16 \%)$.

The wide range of prevalence values observed in these studies has indicated that geographic, gender, races, and genetics differences as well as the big differences in the sample size and criteria of selection play a fundamental role in the varied results of studies of dental anomalies. They could also be explained by local environmental influences and nutrition. This wide range could make the comparison of the result of this study very limiting with other previous studies.

Hypodontia is defined as the failure of development of one or more teeth, is the most commonly occurring dental anomaly affecting the human dentition. Oligodontia is defined as missing more than six teeth, 
and anodontia is a complete absence of the teeth.

Dental agenesis has been reported to be the most common anomaly in the development of the human dentition and the prevalence of dental agenesis was $7.48 \%$ excluding third molar for both sexes together. The prevalence of oligodontia was $0.33 \%$.

This study showed that among missing teeth except third molars, the maxillary lateral incisor was the most lost by $48.61 \%$ followed by mandibular lateral incisor (19.44\%), mandibular central incisor (8.33\%), mandibular second premolar (6.94\%) and maxillary second premolar (5.55\%). The canine, first premolar, maxillary central incisor, second molar were rarely absent. There was no observation about the absence of the maxillary and mandibular first molars.

Hyperdontia is the development of an increased number of teeth, and the additional teeth are termed supernumerary. In this study, Hyperdontia, including supernumerary tooth like paramolar and mesiodens, were seen in 18 (2.99\%) patients out of 601 participants. These results were in par with the study conducted by Gupta et al which showed a prevalence rate of $2.40 \% .{ }^{21}$ The prevalence of supernumerary teeth is between 1 - 3\% with slight higher rate in Asian population, with a strong predilection for anterior region. ${ }^{22}$ Study conducted by Altug- Atac showed a prevalence of $0.36 \%$ of hyperdontia. ${ }^{23}$

Microdontia refers to teeth which are smaller than normal size. Microdontia was observed in $13(2.16 \%)$ of patients. Most common affected teeth was maxillary third molar followed by maxillary laterals. Microdontia was very common in maxilla compared to mandible. The findings of a study conducted by Guttal et al showed a prevalence of $9.14 \% .{ }^{24}$ A study conducted by Brin et al and Ooshima et al showed a prevalence rate of $0.3 \%$ and $8.4 \%$ respectively. ${ }^{25,26}$ Other study by Kocabalkan et al and Ushu et al showed microdontia prevalence of $2 \%$ and $0.7 \%$. 2,27

Macrodontia refers to teeth which are larger than normal size. The occurrence of macrodontia $(0.66 \%)$ was less common than microdontia.

Prevalence rate of transposition of teeth seen in this study was $0.66 \%$. Most common transposition was between maxillary lateral incisor and canine.

Taurodontism is a condition characterized by enlargement of the tooth body at the expense of the roots, with the bifurcation or trifurcation occuring near the apices of the roots. There were $3(0.49 \%)$ cases of taurodontism. There were $2(0.33 \%)$ cases of double tooth, 2 cases of amelogenesis imperfecta and one case of dentinogenesis imperfecta seen in this study. None of any patient had dentine displasia among orthodontic patients of this study.

This study revealed that malocclusion group had statistically non significant relationship with multiple dental anomalies. This study also showed that dental anomalies as a whole are more common in class-III (19.04\%) followed by class-II (15.59\%) and class-I (14.97\%) malocclusion. The finding of this study is contradictory to study by Ramdurg et al that which showed more common dental anomalies in Class-II followed by Class-I and Class-III malocclusion. ${ }^{28}$

Dental anomalies often result in malocclusion and interfere with function, speech, and aesthetics. Thus, appropriate treatments are deemed necessary to correct or improvise this condition.

Long-term multicenter collaborative studies in diverse population groups with greater sample size and inclusion of healthy control as well as incorporation of all types of dental anomalies are suggested to make more comprehensive assessment of dental anomalies.

\section{CONCLUSION}

Prevalence and distribution of some dental anomalies in orthodontic patients of Kathmandu, Nepal differed from other studies. Orthodontists should concern about the difference in dental anomalies in various group of patients. Maxillary lateral incisor was the most commonly missing and microdontic tooth. Dental anomalies might result in malocclusion and interfere with function, speech, and aesthetics. Orthodontists have the responsibility to observe each patient carefully for dental anomalies and have full knowledge of them as it can help to plan the best possible treatments, both esthetically and functionally by comprehensive multidisciplinary treatment to correct or improvise this condition without any complications.

\section{Conflict of interest}

The author declares that there is no conflict of interest regarding the publication of this paper. 


\section{REFERENCES}

1. Jeong KH, Kim D, Song YM, Sung J, Kim YH. Epidemiology and genetics of hypodontia and microdontia: A study of twin families. Angle Orthod. 2014; 85: 980-985.

2. Uslu O, Akcam MO, Evirgen S, Cebeci I. Prevalence of dental anomalies in various malocclusions. Am J Orthod and Dentofacial Orthop. 2009; 135: 328-335

3. Proffit WR. The development of orthodontic problems. In: Proffit WR, editor. Contemporary orthodontics. 2nd ed. St Louis: Mosby; 1997. p. 110.

4. Sogra Y, Mahdjoube GM, Elham K, Shohre TM. Prevalence of dental anomalies in Iranian orthodontic patients. J Dent Oral Hygiene. 2012; 4: 16-20.

5. Afify AR, Zawawi KH. The Prevalence of Dental Anomalies in the Western Region of Saudi Arabia. International Scholarly Research Network. 2012; 1-5.

6. Kositbowornchai S, Keinprasit C, Poomat N. Prevalence and distribution of dental anomalies in pretreatment orthodontic Thai patients. Kerala Dental Journal. 2010; 13: 92-100.

7. Gupta SK, Saxena P, Jaina S, Jain D. Prevalence and distribution of selected developmental dental anomalies in an Indian population. Journal of Oral Science. 2011; 53: 231-238.

8. Altug-Atac AT, Erdem D. Prevalence and distribution of dental anomalies in orthodontic patients. Am J Orthod Dentofacial Orthop. 2007; 131: 510-14.

9. Tantanapornkul W. Prevalence and Distribution of Dental anomalies in Thai Orthodontic Patients. Int J Med Health Sci. $2015 ; 4(2)$ : $165-72$.

10. Khan SQ, Ashraf B, Khan NQ, Hussain B. Prevalence of dental anomalies among orthodontic patients. Pakistan Oral \& Dental Journal. 2015; 35(2): 224-7.

11. Thongudomporn U, Freer TJ. Prevalence of dental anomalies in orthodontic patients. Aust Dent J. 1998; 43(6): 395-8.

12. Efthimia K, Basdra, Kiokpasoglou M, Stellzig A. The Class II Division 2 Craniofacial Type is Associated with Numerous Congenital Tooth Anomalies. Eur J Orthod. 2000; 22: 529-35.

13. Peck S, Peck L, Kataja M. Class II Division 2 malocclusion: A heritable pattern of small teeth in well-developed jaws. Angle Orthod. 1998; 68: 9-20.

14. Angle EH. "Classification of malocclusion". Dent Cosm. 1899: 248-64, 350-7.

15. Soames JV, Southam JC. Oral pathology. 4th edn. Oxford; New York: Oxford University Press. 2005.

16. Vahid-Dastjerdi E, Borzabadi-Farahani A, Mahdian M, Amini N. Non-syndromic hypodontia in an Iranian orthodontic population. J. Oral. Sci. 2010; 52: 455-61.

17. Vahid-Dastjerdi E, Borzabadi-Farahani A, Mahdian M, Amini N. Supernumerary teeth amongst Iranian orthodontic patients. A retrospective radiographic and clinical survey. Acta Odontol. Scand. 2011; 69: 125-8.

18. Anitha, Roopashri G, Maria Priscilla David. Prevalence of developmental dental anomalies - a clinical study. Int J of Contemp Med Research. 2018; 5(3): 22-24.

19. Roslan AA, Rahman NA, Alam MK. Dental anomalies and their treatment modalities/planning in orthodontic patients. J Orthodont Sci. 2018; 7: 16.

20. Baron C, Houchmand-Cuny M., Enkel B., Lopez-Cazaux, S. Prevalence of dental anomalies in French orthodontic patients: A retrospective study. Archives de Pe' diatrie. 2018; 7 (2); 1-5.

21. Saurabh K, Saxena P, Jain S, Jain D. Prevalence and distribution of selected developmental dental anomalies in an Indian population. J oral sci. 2011; 53: 231-38.

22. Neville, Damm, Allen, Bouquot. Oral And Maxillofacial Pathology. 3rd ed. Elsevier Publishers; 2009: $126-7$.

23. Altug-Atac AT, Erdem D. Prevalence and distribution of dental anomalies in orthodontic patients. Am J Ortho Dentofacial Orthop. 2007: 131: 510-14.

24. Guttal KS, Naikmasur VG, Bhargava P, Bathi RJ. Frequency of Developmental Dental Anomalies in the Indian Population. Eur J Dent. 2010; 4: 263-69.

25. Brin I, Becker A, Shalhav M. Position of the maxillary permanent canine in relation to anomalous or missing lateral incisors: a population study. Eur J Orthod. 1986; 8: 12-6.

26. Ooshima T, Ishida R, Mishima K, Sobue S. The prevalence of developmental anomalies of teeth and their association with tooth size in the primary and permanent dentitions of 1650 Japanese children. Int J Paediatr Dent. 1996; 6: 87-94.

27. Kocabalkan E, Ozyemisci N. Restoration of severe hypodontia associated with microdontia by using an overdenture: a clinical report. Chinese Medical Journal (Engl). 2005; 118: 350-352.

28. Ramdurg PK, Mendegeri V, Vanishree BK, Achanur M, Srinivas N. Int J Community Med Public Health. 2016 Jun; 3(6): 1466-1471. 